\title{
Extract of Ginkgo biloba EGb76I Facilitates Extinction of Conditioned Fear Measured by Fear-Potentiated Startle
}

\author{
Yi-Ling Yang', Ya-Wen $\mathrm{Su}^{2}$, Ming-Chong $\mathrm{Ng}^{2}$, Po-Kuan $\mathrm{Chao}^{2}$, Li-Chu Tung ${ }^{2}$ and Kwok-Tung Lu*,2 \\ 'Department of Molecular Biology and Biochemistry, Institute of Biotechnology, National Chia-Yi University, Chia-Yi, Taiwan; ${ }^{2}$ Department of \\ Life Science, National Taiwan Normal University, Taipei, Taiwan
}

\begin{abstract}
A standard extract of Ginkgo biloba (EGb76I) has been used in the treatment of various common geriatric complaints including vertigo, short-term memory loss, hearing loss, lack of attention, or vigilance. We demonstrated that acute systemic administration of EGb76। facilitated the acquisition of conditioned fear. Many studies suggest the neural mechanism underlies extinction is similar to the acquisition. This raises a possibility that EGb76I may modulate and accelerate the fear extinction process. We tested this possibility by using fearpotentiated startle (FPS) on laboratory rats. Acute systemic injection of EGb76I (I0,20, or $50 \mathrm{mg} / \mathrm{kg}) 30$ min before extinction training facilitated extinction in a dose-dependent manner. Intra-amygdaloid infusion of EGb76I (28 ng/side, bilaterally) I 0 min before extinction training also facilitated extinction. Control experiments showed that facilitation effect of EGb76I was not the result of impaired expression of conditioned fear or accelerated forgetting. Rats previously injected with EGb76I showed significant FPS after retraining. Extinction of conditioned fear appeared to result from acute drug effects rather than from toxic action. Systemic administration of EGb76I immediately after extinction training did not facilitate extinction, suggested the EGb76I facilitation effect is contributed to the acquisition phase of extinction learning. Western blot results showed that extinction induced amygdaloid extracellular signal-regulated kinase (ERKI/2) phosphorylation was significantly elevated by EGb76I treatment. Intra-amygdala injection of ERK I/2 inhibitor PD98059 completely blocked the EGb76I effect. Therefore, acute EGb76I administration modulated extinction of conditioned fear by activating ERKI/2.
\end{abstract}

Neuropsychopharmacology (2007) 32, 332-342. doi:I0.I 038/sj.npp. I 30 I060; published online 22 March 2006

Keywords: Ginkgo biloba; EGb76I; fear-potentiated fear; extracellular signal-regulated kinase; extinction

\section{INTRODUCTION}

Herbal extract of the Ginkgo biloba leaves has been cultivated for medicinal properties in China for several thousands years. In recent years, it is increasingly popular in western society as an 'over-the counter' herbal supplement and in prescription drugs (Landes, 1997; O'Hara et al, 1998). A standardized extract of Ginkgo biloba (EGb761) contains $24 \%$ ginkgo-flavone glycosides and $6 \%$ terpenoids (Drieu, 1986). It is used in the treatment of various common geriatric complaints including vertigo, short-term memory loss, hearing loss, and lack of attention or vigilance. In clinical trials, improvement in cognitive function is demonstrated in older people with dementia or ageassociated memory impairment (Curtis-Prior et al, 1999;

\footnotetext{
*Correspondence: Dr K-T Lu, Department of Life Science, National Taiwan Normal University, 88 Ting-Chow Rd, Sec 4, Taipei II6, Taiwan, Tel: +886229333|49 ext. 234, Fax: + 886229312904 , E-mail: ktlu@ntnu.edu.tw

Received 24 August 2005; revised 3 February 2006; accepted 6 February 2006

Online publication: 9 February 2006 at http://www.acnp.org/citations/ Npp020906050530/default.pdf
}

Le Bars et al, 2000). It is also applied to treatment of cerebral vascular disorders (Krieglstein et al, 1995; Le Bars et al, 1997; Diamond et al, 2000). Even though the EGb761 is widely used in prescription drugs, the efficacy of EGb761 as a nootropic agent is somewhat controversial. Some clinical trials failed to find any improvement in older people with dementia or age-associated memory impairment (Van Dongen et al, 2000).

Two possible mechanisms may account for the behavioral effects of EGb761 observed in aged animals. EGb761 increases cerebral blood flow (Krieglstein et al, 1986). The flavonoid constituents of EGb761 possess free-radical scavenging properties (Clostre, 2000). The first possible mechanism is the ability of EGb761 to serve as a protective agent, protecting against oxidative stress and preventing mitochondrial aging (Millan et al, 1998). Thus, it is a buffer against rapid age-related decline in mental function. The second possible mechanism is the ability of EGb761 to serve as a cognitive enhancer (Das et al, 2002) and anxiolytic agent to counter stress effects. Several laboratories have documented anxiolytic effects associated with repeated administration of EGb761 or preparations containing EGb761. Animals cotreated with extracts of Zingiber 
officinale and Gingko biloba, increase in time in the open arms of an elevated plus maze (Hasenöhrl et al, 1996, 1998). EGb761 restores successful avoidance behavior and increases food consumption in emotional hypophagia test (Porsolt et al, 1990). EGb761 can also serve as an antistress buffer, attenuating the increase in anxiety typically observed in animals after cold-water exposure (Ward et al, 2002). These findings suggest that EGb761 may facilitate successful behavioral adaptation to stressors or noxious stimuli.

We recently reported that acute systemic administration of EGb761 facilitated the acquisition of conditioned fear (Yang et al, 2005a). Several studies suggest that the neural mechanism underlying extinction is similar to the acquisition (Lu et al, 2001; Lin et al, 2003a, b; Yang and Lu, 2005). It raises the possibility that EGb761 can modulate extinction and accelerate the extinction process. The general purpose of this study was to further characterize the acute mood and cognitive effects of acute administration of EGb761 and evaluate the possibility that acute administration of EGb761 modulates the extinction process. To achieve these goals, we used the fear-potentiated startle paradigm (FPS) to evaluate the effect of EGb761 on the extinction of conditioned fear.

\section{MATERIALS AND METHODS}

\section{Animals}

Adult male Sprague-Dawley rats (obtained from the animal center of National Taiwan University, Taiwan) weighing 250-350 g were housed in groups of four rats in a temperature $\left(24^{\circ} \mathrm{C}\right)$ - controlled animal colony with continuous access to food and water. Rats were kept on a 12/12 light-dark cycle with lights on at $0700 \mathrm{~h}$. All behavioral procedures took place during the light cycle. All procedures were accordance with the National Institutes of Health Guide for Care and Use of Laboratory Animals and the guidelines of the Institutional Animal Care and Use Committee at the National Taiwan Normal University.

\section{Surgery}

All surgeries were carried out under sodium pentobarbital (50 mg/kg, intraperitoneal (i.p.)) anesthesia. Once anesthetized, rats were placed in a Kopf stereotaxic instrument, the skull was exposed, and two 22-gauge guide cannulas (model C313G, Plastic-one Products, Roanoke, VA, USA) were implanted bilaterally into the basolateral nucleus of the amygdala (BLA) (AP, $-2.8 ; \mathrm{DV},-7.0, \mathrm{ML}, \pm 5.0$ from the bregma). Size 0 insect pins (Carolina Biological Supply, Burlington, NC, USA) were inserted into each cannula to prevent clogging. These extended approximately $2 \mathrm{~mm}$ past the end of the guide cannula. Screws were anchored to the skull and the assembly was cemented in place using dental cement (Plastic-one Products, Roanoke, VA, USA). Rats received a topical antibiotic (penicillin) each day for the first 3 days after the surgery to reduce the risk of infection.

\section{Behavioral Procedures}

Extinction of the conditioned fear was measured using the potentiated startle paradigm (Cassella and Davis, 1986; Lu et al, 2001; Walker et al, 2002; Yang and Lu, 2005; Yang et $a l, 2005 \mathrm{~b})$. Rats were trained and tested in a startle chamber (San Diego Instruments, San Diego, CA, USA). Each chamber consisted of an $8.6 \mathrm{~cm}$ diameter, $20 \mathrm{~cm}$ long Plexiglas cylinder mounted on a Plexiglas base. A grid floor insert made of seven $4-\mathrm{mm}$ diameter stainless steel bars placed $4 \mathrm{~mm}$ apart was mounted inside the Plexiglas cylinder to deliver footshocks. The delivery of the acoustic stimulus, light, footshock, and measurement of the startle response were controlled by computer. The cage movement results in the displacement of an accelerometer. Startle amplitude was defined as peak accelerometer voltage within $200 \mathrm{~ms}$ after startle stimulus onset.

The behavioral procedures common to all experiments consisted of an acclimation phase, a baseline startle test phase, a fear conditioning phase, a pre-extinction test, an extinction training, and a postextinction test or FPS test (see Figures 1a, 2a, 3a and 4a).

Acclimation. On each of three consecutive days, rats were placed into the test chambers for $10 \mathrm{~min}$ and then returned to their home cages.

Baseline startle test. On each of the next two consecutive days, animals were placed in the test chambers and presented with 30 95-dB startle stimuli at a 30-s interstimulus interval (ISI). Animals whose baseline startle was $<1 \%$ of the measurable level were not included in later analyses.

Fear conditioning. After $24 \mathrm{~h}$, rats were returned to the test chambers and $5 \mathrm{~min}$ later given the first of 10 lightfootshock pairings. The shock (unconditioned stimulus) was delivered during the last $0.5 \mathrm{~s}$ of the $3.7 \mathrm{~s}$ light (conditioned stimulus (CS)). The average intertrial interval was $4 \mathrm{~min}$ (range $=3-5 \mathrm{~min}$ ) and the shock intensity was $0.6 \mathrm{~mA}$.

Pre-extinction test. At $24 \mathrm{~h}$ after fear conditioning, rats were returned to the test chambers and $5 \mathrm{~min}$ later presented with 30 startle-eliciting noise bursts $(95 \mathrm{~dB}-30 \mathrm{~s}$ ISI). These initial startle stimuli were used to habituate the startle response to a stable baseline before the light-noise test trials that followed. After $30 \mathrm{~s}$, a total of 20 startleeliciting noise bursts were presented, 10 in darkness (noise alone) and 10 in $3.2 \mathrm{~s}$ after onset of the $3.7 \mathrm{~s}$ light (lightnoise) in a balanced, irregular order at a 30 -s ISI. Percent FPS was computed as ((startle amplitude on light-noise minus noise-alone trials $) /$ noise-alone trials $) \times 100$. Based on these data, the rats were divided into equal size groups that had comparable mean levels of percent FPS. Animals with less than $50 \%$ FPS during the pre-extinction test were not used.

Extinction training. Extinction training (cue exposure) is defined as the repetitive exposure to the CS cue (light) in the absence of the unCS. At $24 \mathrm{~h}$ after the pre-extinction test, rats were returned to the test chamber and $5 \mathrm{~min}$ later presented with $30,3.7 \mathrm{~s}$ light exposures at a 30 -s ISI. Context control groups (context exposure) remained in the test cages for the same amount of time but did not receive light presentations. Extinction training was performed for varying number of consecutive days as described below.

Postextinction test. At $24 \mathrm{~h}$ after the last extinction training period, rats were returned to the test chamber and 5 min later presented with 30 95-dB leader stimuli 
a
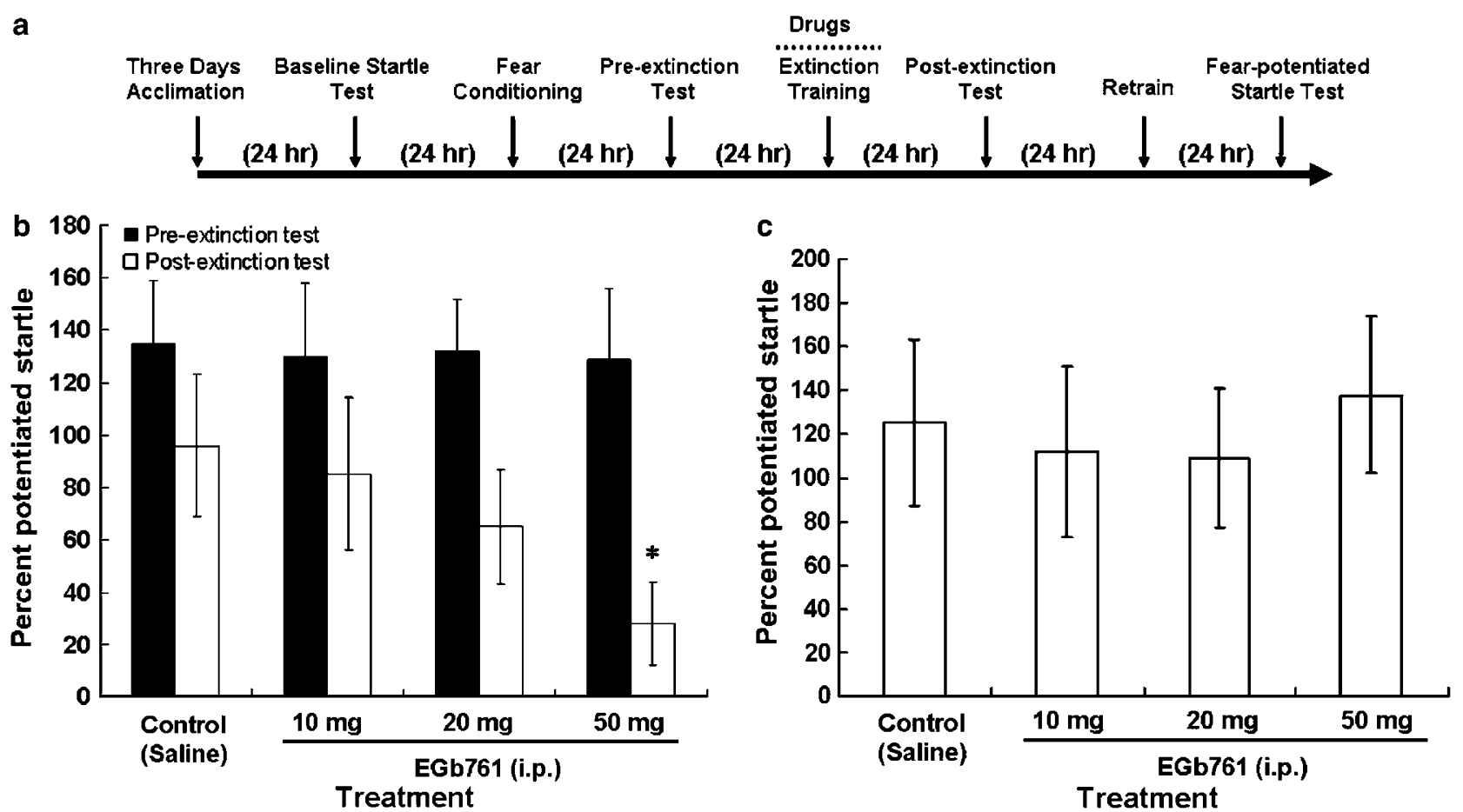

Figure I Systemic administration of Ginkgo biloba extracts EGb76I facilitated extinction of conditioned fear in a dose-dependent manner. (a) Timeline of procedures for experiment I. (b) Percent fear-potentiated startle measured in a pre-extinction test and in a postextinction test. Rats in each group underwent systemic administration of saline or EGb76I (I0,20, or $50 \mathrm{mg} / \mathrm{kg}) 30 \mathrm{~min}$ before a single session of extinction training. (c) The same animals used were retrained. After $24 \mathrm{~h}$, they were tested for fear-potentiated startle in the absence of drugs (fear-potentiated startle test). Values are mean \pm SEM, $* P<0.05$ compared to the saline control.

for a habituated startle baseline. This was followed by a total of 60 startle-eliciting noise bursts, 30 in darkness (noise alone) and 30 presented $3.2 \mathrm{~s}$ after onset of the $3.7 \mathrm{~s}$ light (light-noise) in a balanced, irregular order at a 30 -s ISI. Results were evaluated as with the pre-extinction test.

FPS test. At $24 \mathrm{~h}$ after the fear conditioning or extinction training, rats were returned to the test chamber and testing for the FPS (procedure is similar to the postextinction test described above).

\section{Drug Treatment}

The standard extract of Ginkgo biloba containing 24\% ginkgo-flavone glycosides and $6 \%$ terpenoids was supplied by Mattern et Partner (Starnberg, Germany) and freshly dissolved in saline with the help of ultrasound and injected i.p. with a 26 gauge injection needle connected to a $1 \mathrm{ml}$ syringe $30 \mathrm{~min}$ before extinction training (experiment $1,2,5$, and 6) or FPS test (experiment 4) or immediately after extinction training (experiment 3). The particular doses of EGb761 used here were based on Yang et al, (2005a) with slightly modification. ERK1/2 inhibitor PD98059 (200 ng in $1 \mu \mathrm{l}$ of 20\% DMSO; Calbiochem, La Jolla, CA, USA) (Lu et al, 2001) or 20\% DMSO was infused into the BLA $10 \mathrm{~min}$ before saline or EGb761 $(50 \mathrm{mg} / \mathrm{kg})$ injection (experiment 6). EGb761 (2.8 ng in $1 \mu \mathrm{l}$ of ACSF; Dr Willmar Schwabe, Karlsruhe Germany) or ACSF was infused into the BLA 10 min before extinction training (experiment 7).

\section{Western Blot Analysis}

Animals were decapitated $15 \mathrm{~min}$ after completion of experiment 6. Lateral and basolateral subregions of the amygdala were collected and briefly sonicated in ice-cold buffer (50 mM Tris- $\mathrm{HCl}(\mathrm{pH} 7.8), 50 \mathrm{mM} \mathrm{NaCl}, 10 \mathrm{mM}$ EGTA, $5 \mathrm{mM}$ ethylenediaminetetraacetic acid, $2 \mathrm{mM}$ sodium pyrophosphate, $4 \mathrm{mM}$ para-nitrophenylphosphate, $1 \mathrm{mM}$ sodium orthovanadate, $1 \mathrm{mM}$ phenylmethylsulfonyl fluoride (PMSP), $20 \mathrm{ng} / \mathrm{ml}$ leupeptin, and $4 \mathrm{ng} / \mathrm{ml}$ aprotinin). Following sonication, the soluble extract was obtained after pelleting the crude membrane fraction by centrifuging at $50000 \mathrm{~g}$ at $4^{\circ} \mathrm{C}$. Protein concentration in the soluble fraction was then measured using a Bradford assay, with bovine serum albumin as the standard. Equivalent amounts of protein for each sample were resolved in $10 \%$ sodium dodecyl sulfate (SDS)-polyacrylamide gels, blotted electrophoreticaly to immobilon, and blocked overnight in 5\% skim milk (in TBS). (Cell Signaling Technology Inc., USA). Blots were incubated with antiphospho-ERK1/2 antibody (New England Biolabs, USA) or anti-ERK1/2 antibody (BD Transduction Laboratories, USA). Bands were detected with an enhanced chemiluminescence Western blotting analysis system (RPN 2108; Amersham International, Amersham, UK).

\section{Statistics}

ANOVA on percent potentiation scores was the primary statistic. Between-group comparisons were made using twotailed $t$-tests for independent samples. The criterion for significance for all comparisons was $P<0.05$. 

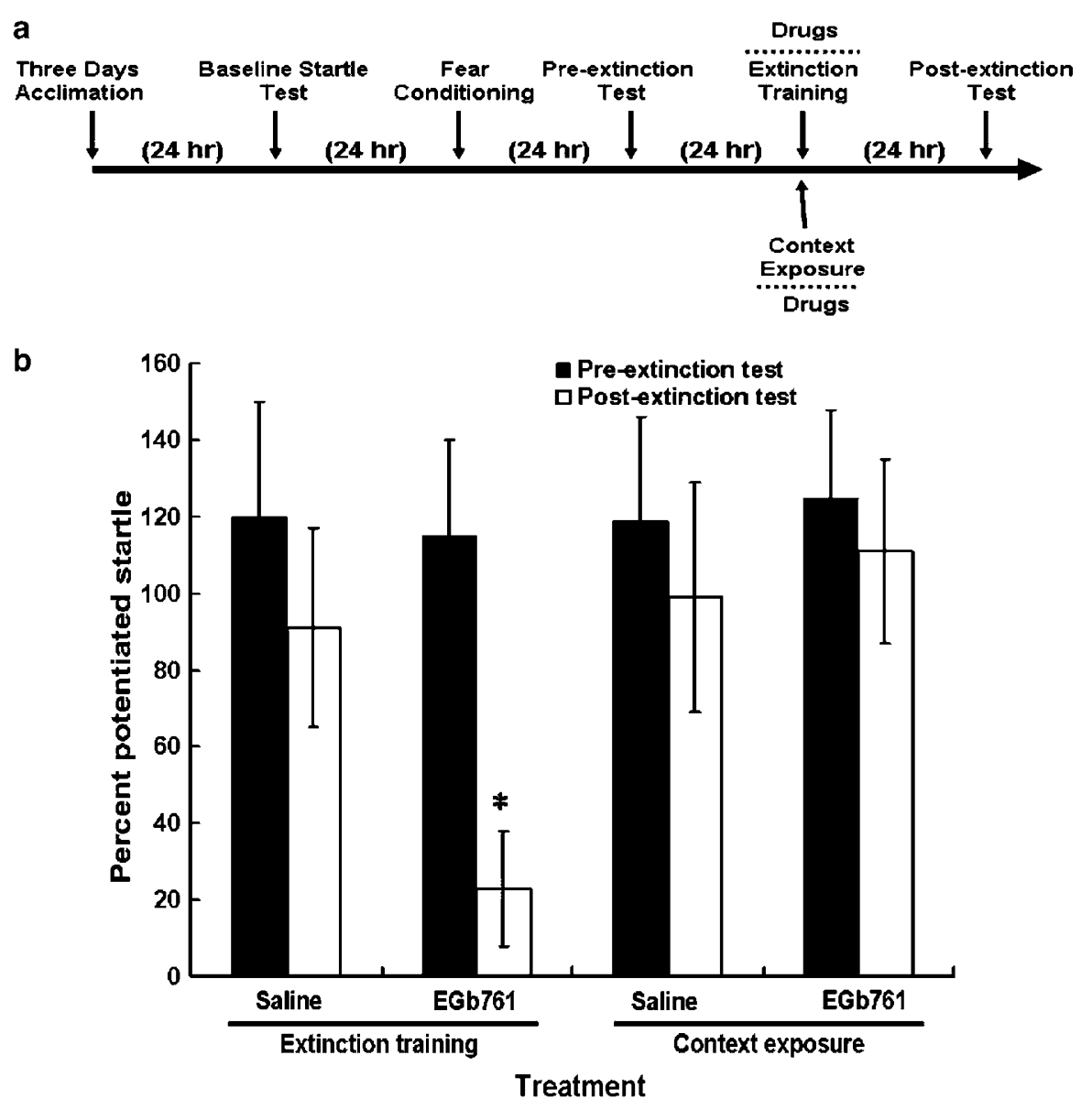

Figure 2 Facilitation effect of EGb76I on extinction required extinction training. (a) Timeline of procedures for experiment 2. (b) Percent fearpotentiated startle measured in a pre-extinction test and a postextinction test. Rats in each group underwent systemic administration of saline or EGb76 I $(50 \mathrm{mg} / \mathrm{kg}) 30 \mathrm{~min}$ before a single session of extinction training (with CS) or context exposure (without CS). After $24 \mathrm{~h}$, animals were tested for fearpotentiated startle in the absence of drugs. Values are mean \pm SEM, $* P<0.05$ compared to the saline control group.

\section{RESULTS}

\section{Experiment 1: Systemic Administration of Ginkgo biloba Extracts EGb761 Facilitated Extinction of Conditioned Fear}

This experiment assessed the effect of Ginkgo biloba extracts EGb761 on the extinction of conditioned fear. Since a single day of extinction training with cue exposure leads to a $35 \%$ decrease in FPS, but 2-3 days leads to near complete extinction (Lu et al, 2001; Walker et al, 2002; Yang and Lu, 2005), we reasoned that an acceleration of extinction would be best detected after a single session of extinction training. Initially, 38 rats were used. Six were excluded for showing $<50 \%$ FPS during the pre-extinction test. The final 32 rats were assigned to four different groups of eight animals based on their level of FPS in the pre-extinction test. At $24 \mathrm{~h}$ after the pre-extinction test, they received one of the following treatments: saline (control group), $10 \mathrm{mg} / \mathrm{kg}$ EGb761 (lowdose group), $20 \mathrm{mg} / \mathrm{kg}$ EGb761 (medium-dose group), and $50 \mathrm{mg} / \mathrm{kg}$ EGb761 (high-dose group). The doses of EGb761 we used here followed the study of Yang et al (2005a). Saline and EGb761 were injected i.p. $30 \mathrm{~min}$ before extinction training. After $24 \mathrm{~h}$, rats were tested for FPS in the absence of drugs. EGb761 facilitated extinction of conditioned fear in a dose-dependent manner (Figure 1b), eliciting a significant dose effect $\left(F_{(3,28)}=3.162 ; P<0.05\right)$ showing a significant linear trend $\left(F_{(1,28)}=6.76 ; P<0.05\right)$. The medium-dose group showed a nonsignificant trend in facilitating extinction. FPS was significantly lower in rats injected with $50 \mathrm{mg} / \mathrm{kg}$ EGb761 before extinction training $\left(\mathrm{t}_{(14)}=2.256, P<0.05\right)$ compared to the control group. As $50 \mathrm{mg} / \mathrm{kg}$ EGb761 produced a significant effect, we used this dose in subsequent experiments (experiment 2, 3, and 4). Previous studies have shown that lesions of the BLA block expression of FPS (Campeau and Davis, 1995). Since EGb761 may have a toxic effect on BLA, resulting in misinterpretation of its effects on extinction, all rats of experiment 1 were retrained and tested $24 \mathrm{~h}$ later. All rats, whether injected with EGb761 or saline, showed a significant FPS (Figure 1c). Thus the facilitation effect of EGb761 observed during the postextinction test appeared to result from an acute drug effect rather than from a more permanent and, perhaps toxic, action of EGb761.

\section{Experiment 2: Facilitation Effect of EGb761 on Extinction Required Extinction Training}

EGb761 may have nonspecific effects that accelerate the forgetting process or impair expression of conditioned fear. This can result in misinterpretation of its facilitation effects on extinction. To test this possibility, 32 rats received fear 
a

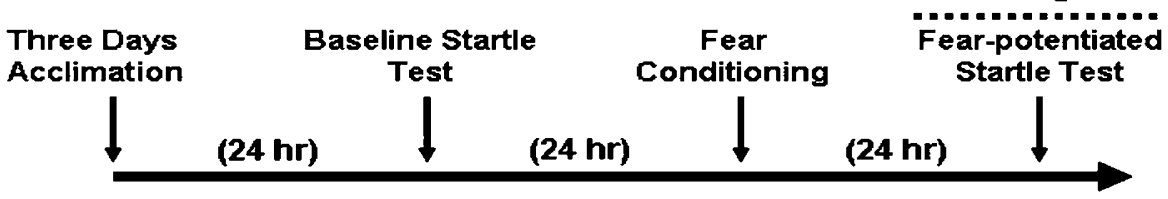

b

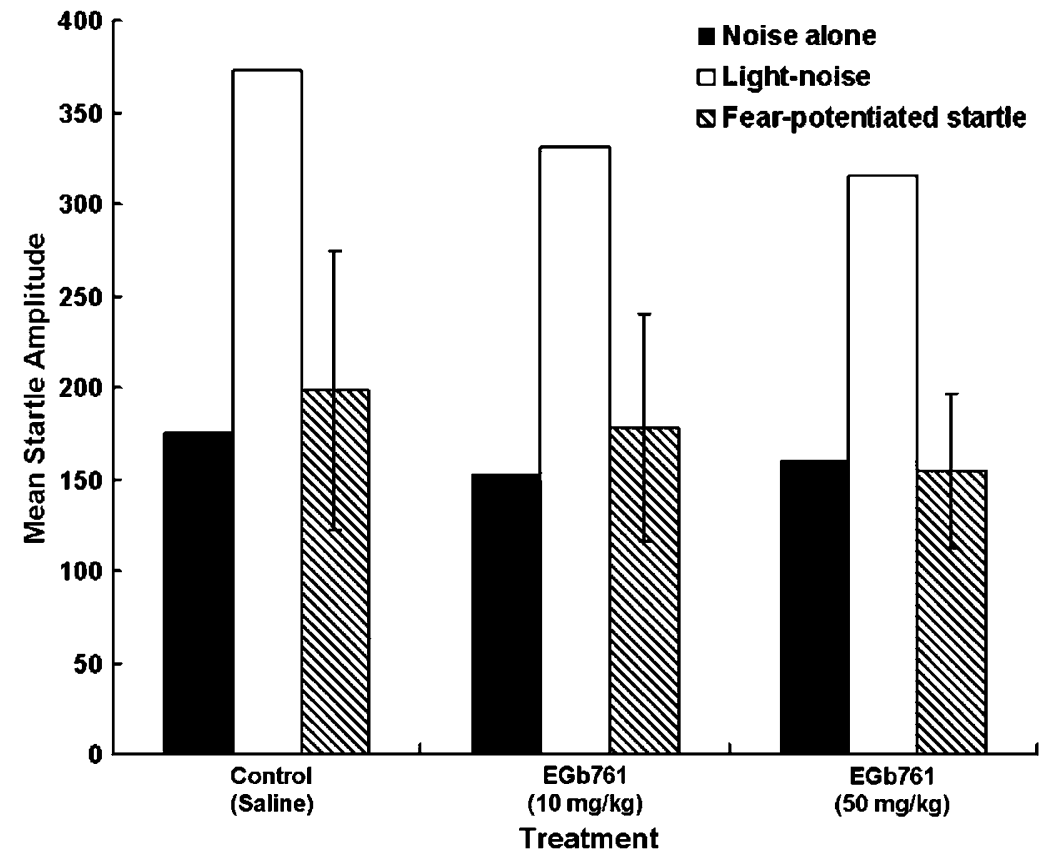

Figure 3 Effect of pretest administration of EGb76I on fear-potentiated startle. (a) Timeline of procedures for experiment 3. (b) Percent fear-potentiated startle measured in a fear-potentiated startle test. Rats in each group underwent either saline or EGb76I (50 mg/kg) $30 \mathrm{~min}$ before the fear-potentiated startle test. values are mean \pm SEM.

conditioning, extinction training, and testing for FPS. Initially, 38 rats were used, but six were excluded for the same reason rats were excluded in experiment 1 . Rats were then assigned into four groups of eight based on their level of FPS in the pre-extinction test. Groups 1-2 received injections of saline and EGb761, respectively, $30 \mathrm{~min}$ before a single session of extinction training. After $24 \mathrm{~h}$, rats were tested for FPS in the absence of drugs. Groups 3-4 received the injection treatments described above, but were placed in the test chamber without extinction training (context exposure only). Results of an ANOVA indicated a significant treatment (saline and EGb761) by training (extinction training vs context exposure $)$ interaction $\left(\mathrm{F}_{(1,28)}=8.09 ; \quad P<0.05\right)$. Administration of EGb761 significantly facilitated extinction of conditioned fear $\left(\mathrm{t}_{(14)}=2.48 ; P<0.05\right)$. The facilitation effect of EGb761 required extinction training. Neither saline nor EGb761 affected extinction in the context exposure treated groups (group 4-5). The facilitation effect of EGb761 on the extinction was not the result of impaired expression of conditioned fear or of accelerated forgetting.

\section{Experiment 3: Effect of Pretest EGb761 Administration on FPS}

This experiment evaluated whether the effect of the EGb761 was secondary to effect on fear or on CS processing. For example, if EGb761 enhances CS-elicited fear, this might facilitate extinction by increasing the discrepancy between that predicted by CS and what actually occurs. To evaluate this possibility, 16 rats received acclimation, baseline startle test and fear conditioning (21 rats were used initially, but five of them were excluded for the same reason described previously). After $24 \mathrm{~h}$, rats were injected with saline or EGb761. At $30 \mathrm{~min}$ after the injections, rats were tested for FPS. As shown in Figure 3, at the dose of EGb761 used here did not significantly influenced FPS. Thus, it is unlikely that EGb761 influenced extinction by increasing fear or by disrupting CS processing.

\section{Experiment 4: Systemic Administration of EGb761 after Extinction Training did not Facilitate Extinction of Conditioned Fear}

Recent studies show systemic infusion of glutamate NMDA receptor agonist D-cycloserine (DCS) (Ledgerwood et al, 2003; Yang and Lu, 2005) or glucocorticoid agonist dexamethasone (DEX) (Yang et al, 2005b) after extinction training facilitate extinction. This suggests that DCS and DEX are involved in the postlearning consolidation phase of the extinction memory. Postextinction training administration of EGb761 might also facilitate consolidation of extinction learning. To test this hypothesis, 16 rats received 


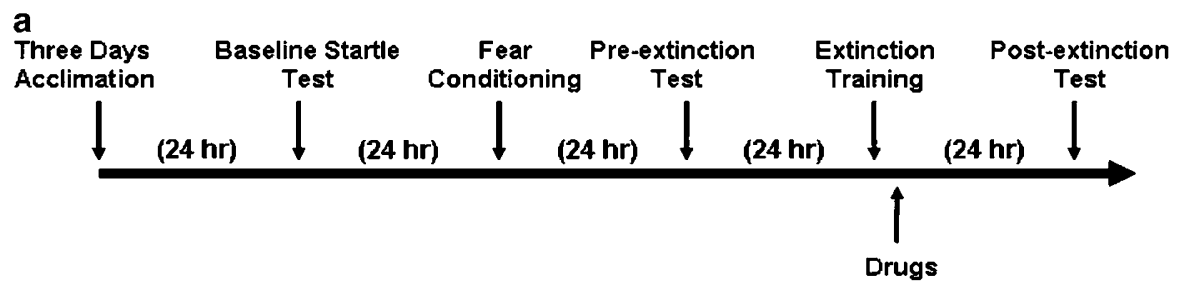

b

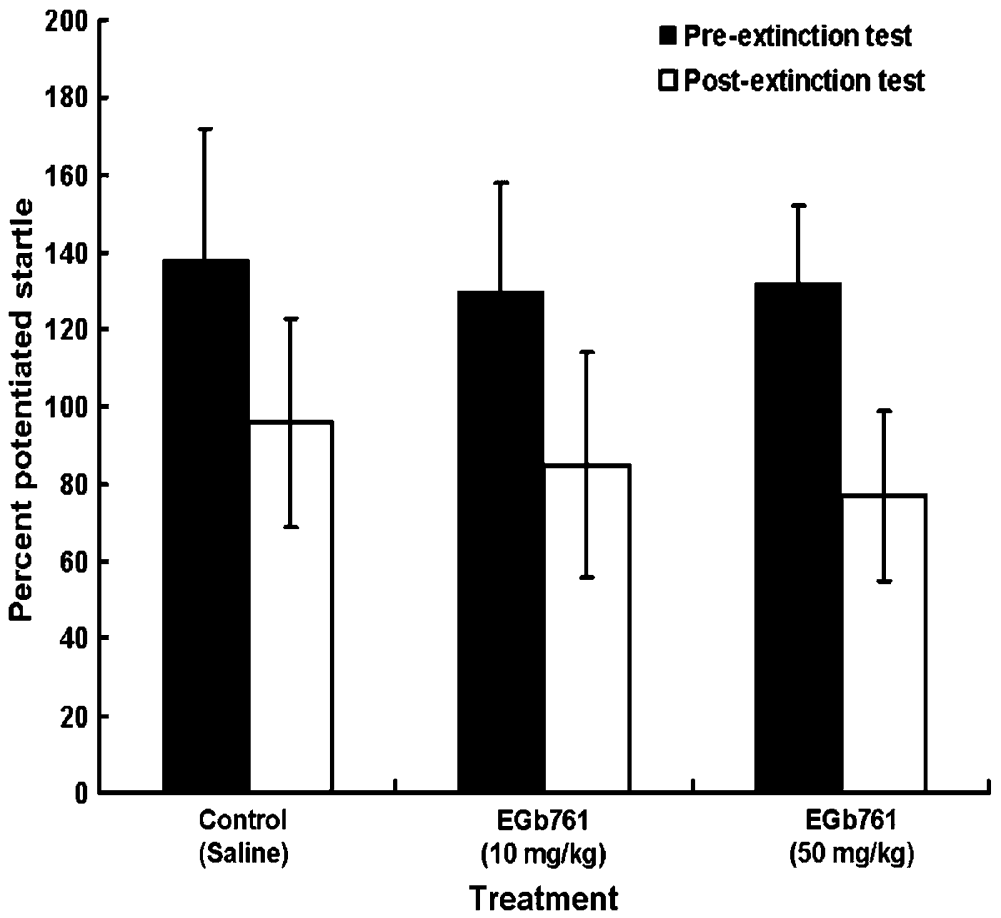

Figure 4 Systemic administration of EGb76I after extinction training did not facilitate extinction of conditioned fear. (a) Timeline of procedures for experiment 4. (b) Percent fear-potentiated startle measured in a pre-extinction test and in a postextinction test. Rat in each group underwent systemic injection of saline or EGb76I $(50 \mathrm{mg} / \mathrm{kg})$ immediately after a single session of extinction training. After $24 \mathrm{~h}$, animals were tested for fear-potentiated startle in the absence of drugs. Values are mean \pm SEM.

fear conditioning, extinction training, and testing for FPS. Initially, 20 rats were used, but four were excluded. Rats were then randomly assigned to two different groups and received saline or EGb761 $(50 \mathrm{mg} / \mathrm{kg})$ immediately after extinction training. Results showed that systemic administration of EGb761 after extinction training did not facilitate extinction of conditioned fear (Figure 4b). Therefore, EGb761 did not influence the memory consolidation phase of extinction.

\section{Experiment 5: Systemic Administration of EGb761 Enhanced Activation of ERKs Induced by Extinction Training}

The amygdaloid ERKs signal cascade is essential for the extinction of conditioned fear (Lu et al, 2001; Yang et al, 2005b; Yang and Lu, 2005). Therefore, ERKs may also be involved in the facilitation effect of EGb761 on extinction. To test this possibility, 24 rats received fear conditioning, extinction training, and testing for FPS. Initially, 22 rats were used, but four were excluded. Animals received one of the following treatments: Extinction training without injection (control group), injection of $50 \mathrm{mg} / \mathrm{kg}$ EGb761 followed $15 \mathrm{~min}$ later by a single session of extinction training $(\mathrm{EGb}+\mathrm{EXT})$, injection of $50 \mathrm{mg} / \mathrm{kg}$ EGb761 followed 15 min later with context exposure (EGb + context), and injection of $50 \mathrm{mg} / \mathrm{kg}$ EGb761 without extinction training or context exposure (EGb alone). Animals were decapitated at 15 min after extinction training or context exposure. The lateral and basolateral subregions of the amygdala were tested with Western blot analysis. Compared with the control, the ERKs phosphorylation was significantly elevated in the BLA after treatment with both extinction training and EGb761 (Figure 5b, lane 2). Neither EGb761 with context exposure nor EGb761 only showed extinction training enhancement of ERK1/2 activation (Figure 5b, lane 3 and 4). The EGb761 enhancement of the extinction of fear conditioning might be mediated by the amygdaloid ERK1/2 signaling cascade.

\section{Experiment 6: Intra-Amygdala Infusion of ERK1/2 Inhibitor PD98059 Blocked the Facilitation Effect EGb761 on Extinction}

To test the role of a ERKs-dependent signaling cascade in the EGb761 enhancement effect on the extinction of fear conditioning, 32 rats received fear conditioning, extinction training, and testing for FPS (40 rats were used initially, but 
a

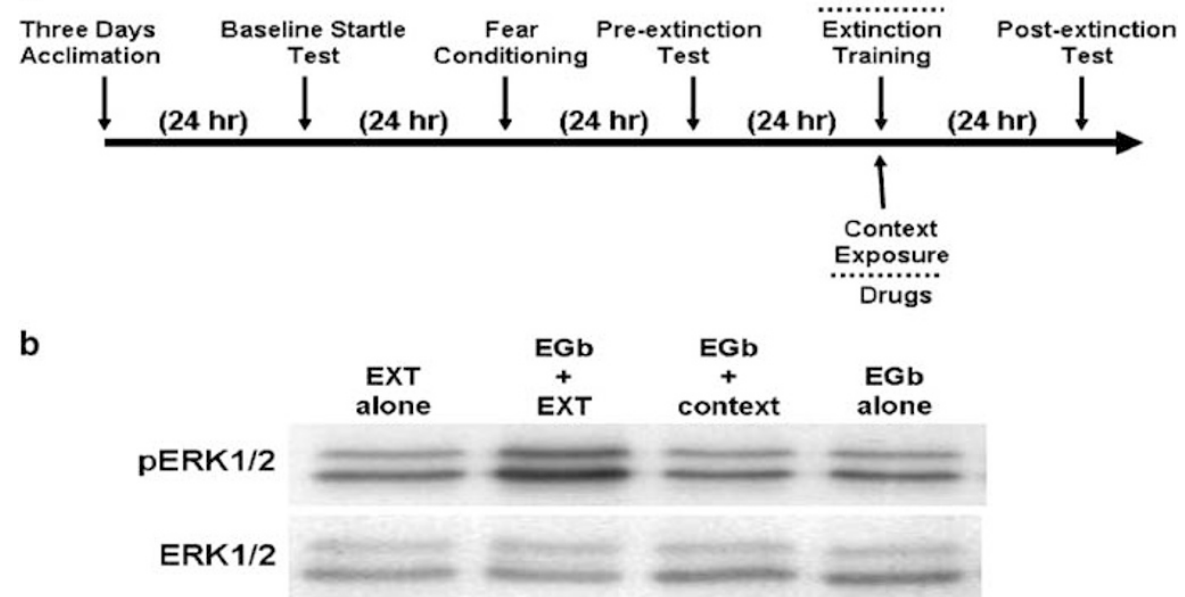

C
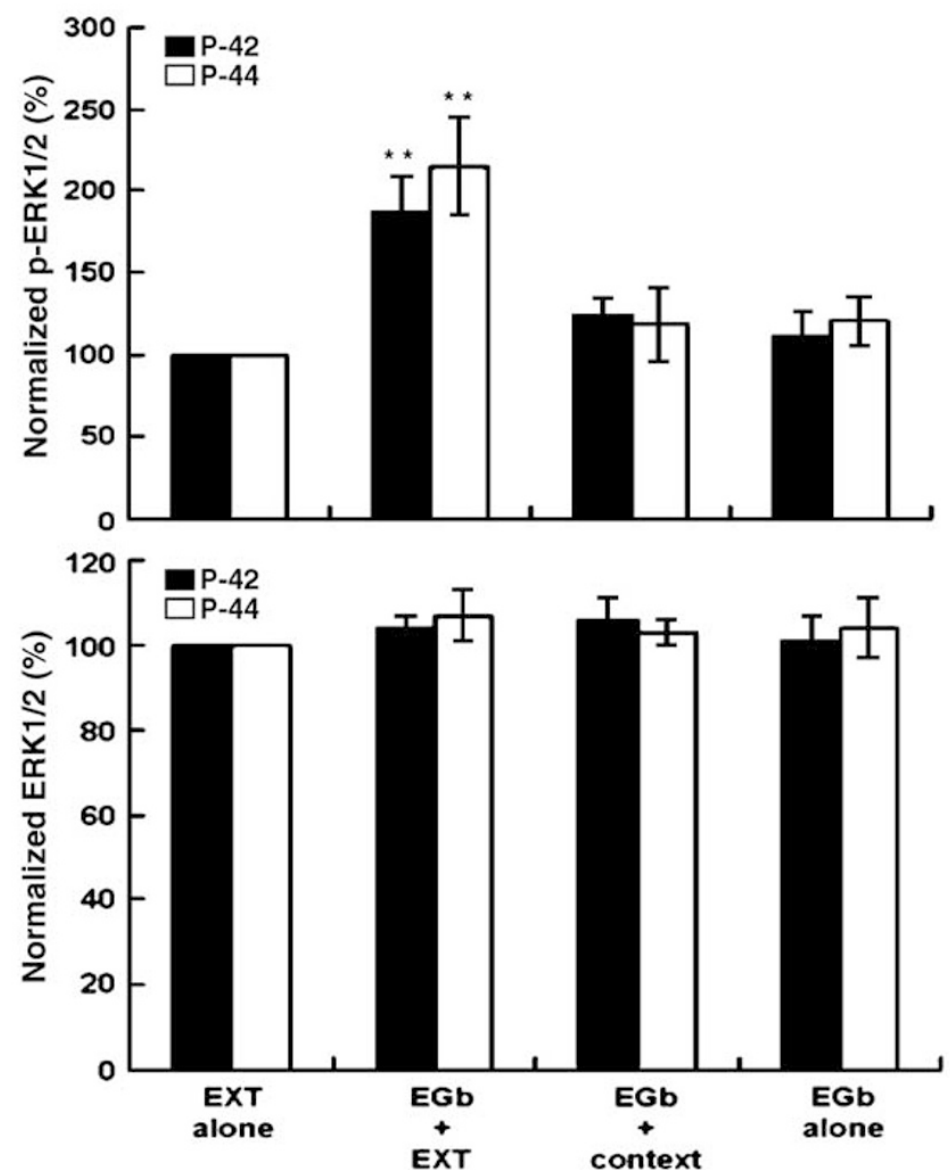

Figure 5 Systemic administration of EGb76I enhanced activation of MAPK induced by extinction training. (a) Timeline of procedures for experiment 5. (b) Representative Western blot and densitometric analysis of the expression of ERKI/2 and phosphorylated ERKI/2 in amygdala among different groups. Rat in each group underwent extinction training only (control group), injection of $50 \mathrm{mg} / \mathrm{kg}$ EGb76I plus extinction training (EGb + EXT), injection of $50 \mathrm{mg} / \mathrm{kg}$ EGb76I plus context exposure (EGb + context), and injection of $50 \mathrm{mg} / \mathrm{kg}$ EGb76I only (EGb alone). Data are presented as the mean \pm SEM ( $n=6$ for each group), $* * *=P<0.01$ compared to the control group.

eight were excluded). They were then randomly assigned to four different groups and received one of the following treatments: vehicle + saline $(\mathrm{VEH}+\mathrm{SAL})$, vehicle $+\mathrm{EGb761}$ $(\mathrm{VEH}+\mathrm{EGb})$, PD98059 + EGb761 (PD + EGb), and PD98059 + saline $(\mathrm{PD}+\mathrm{SAL})$. The ERK1/2 inhibitor PD98059 or vehicle was infused into the BLA 10 min before the injection of EGb761 or saline. Animals were then returned to their cage. At $30 \mathrm{~min}$ injection of EGb761 or saline, animals were subjected to a single session of extinction training. As shown in Figure 6, DMSO or PD98059 (200 ng/side, bilaterally) were given $10 \mathrm{~min}$ before i.p. injection of saline or EGb761 $(50 \mathrm{mg} / \mathrm{kg})$. Rats were returned to their 


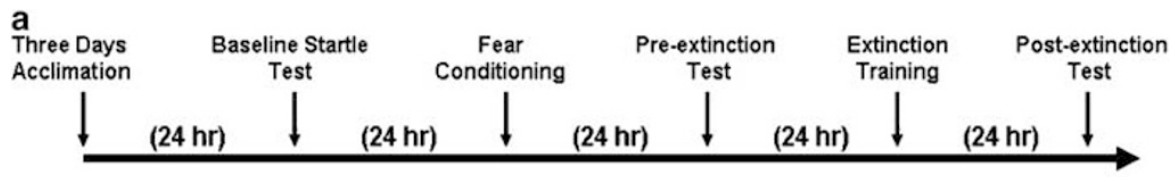

b
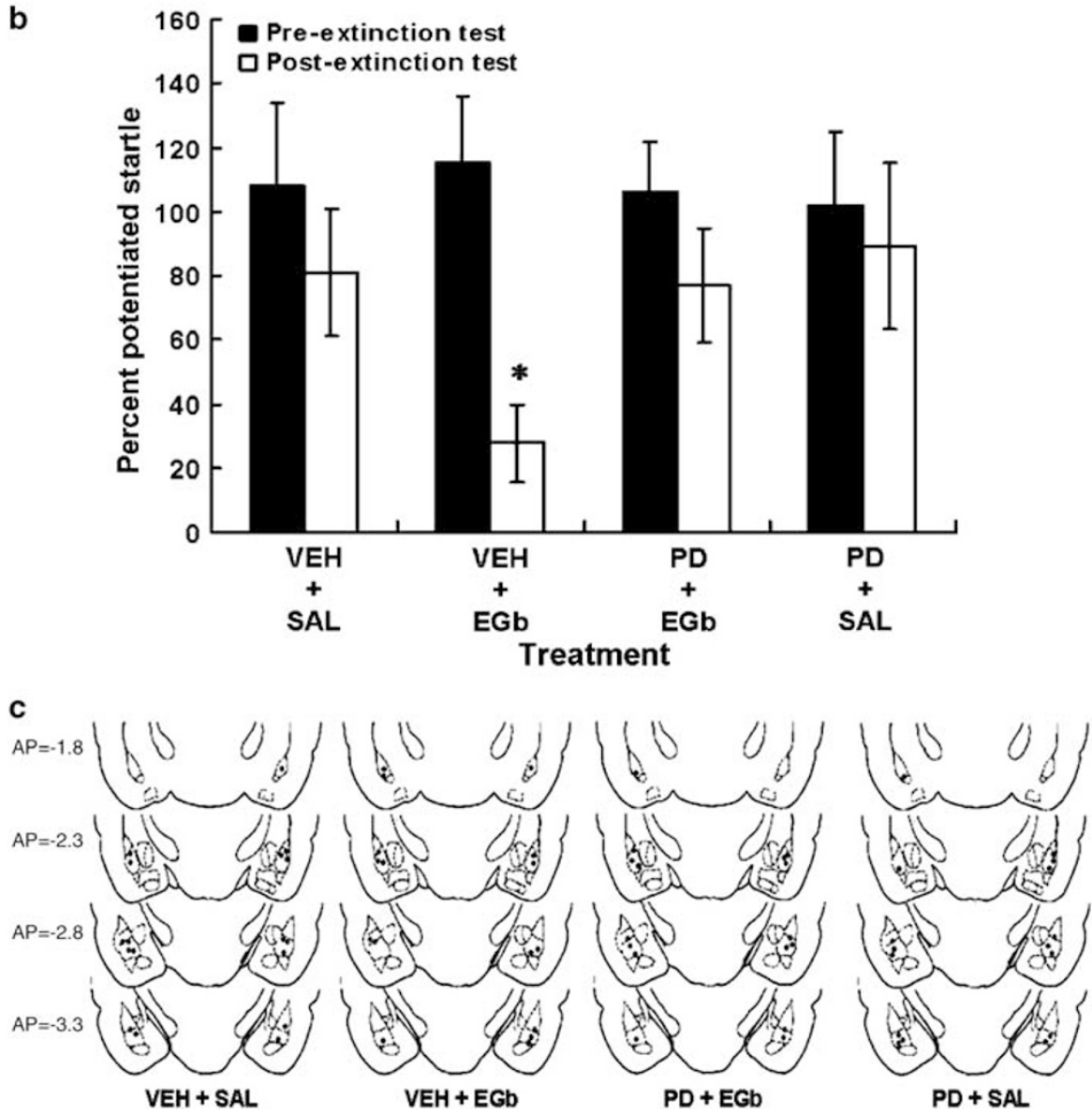

Figure 6 Intra-amygdala infusion of the MAPK inhibitors blocked the facilitation effect of EGb76I on extinction. (a) Timeline of procedures for experiment 6. (b) Cannula was placed in the BLA. Percent fear-potentiated startle measured in a pre-extinction test and a postextinction test. Rats in each group were injected with either vehicle + saline (VEH + SAL); vehicle + EGb76I (VEH + EGb), PD98059 + EGb76I (PD + EGb), and PD98059 + saline $(\mathrm{PD}+\mathrm{SAL})$ before a single session of extinction training. After $24 \mathrm{~h}$, animals were tested for fear-potentiated startle in the absence of drug (values are mean $\pm \mathrm{SEM}$, *P $<0.05$ versus $\mathrm{VEH}+\mathrm{SAL}$ group. (c) Cannula tip placements transcribed onto atlas plates adapted from Paxinos and Watson (1997).

cages for $30 \mathrm{~min}$ before a single session of extinction training. After $24 \mathrm{~h}$, animals were tested for FPS in the absence of drugs. Results showed that there is a significant overall difference between treatments. Figure 6 shows that administration of EGb761 facilitated extinction of conditioned fear $(\mathrm{VEH}+\mathrm{EGb})$ when compared to the control group $(\mathrm{VEH}+\mathrm{SAL}) \quad\left(\mathrm{t}_{(14)}=3.12, \quad P<0.05\right)$. This effect was blocked by coadministration of the ERK1/2 inhibitor PD98059 (PD + EGb) $\left(\mathrm{t}_{(14)}=3.08 ; P<0.05\right.$ and $\mathrm{t}_{(14)}=3.29 ; P<0.05$ respectively) when compared to the $\mathrm{VEH}+\mathrm{EGb}$ group. With the single extinction training session used in this experiment, PD98059 alone (PD + $\mathrm{SAL}$ ) at this dose did not have any effects on the extinction compared to control group (VEH $+\mathrm{SAL})\left(\mathrm{t}_{(14)}=0.07\right.$ and $\mathrm{t}_{(14)}=0.36$, respectively). Therefore, an ERK1/2-dependent signaling cascade most likely mediated the facilitation effect of EGb761.

\section{Experiment 7: Intra-Amygdala Administration of EGb761 Facilitated Extinction of Conditioned Fear}

We tested the role of BLA in the EGb761 enhancement of extinction of fear conditioning. Specifically, we were interested in whether intra-amygdala infusion of EGb761 mimics the effect of systemic administered EGb761. Sixteen rats with intra-amygdala cannulation received fear conditioning, extinction training, and testing for FPS. Initially, 22 were used, but six were excluded. Rats were assigned into two groups of eight based on their level of FPS in the preextinction test. The groups received one of the following treatments: infusion of ACSF alone (control group) or infusion ( $2.8 \mathrm{ng} / \mathrm{side}$, bilaterally) of EGb761 (EGb group). This dose of EGb761 was chosen based on our pilot experiments which suggested higher doses may have toxic effects (data not shown). ACSF and EGb761 were infused 
a
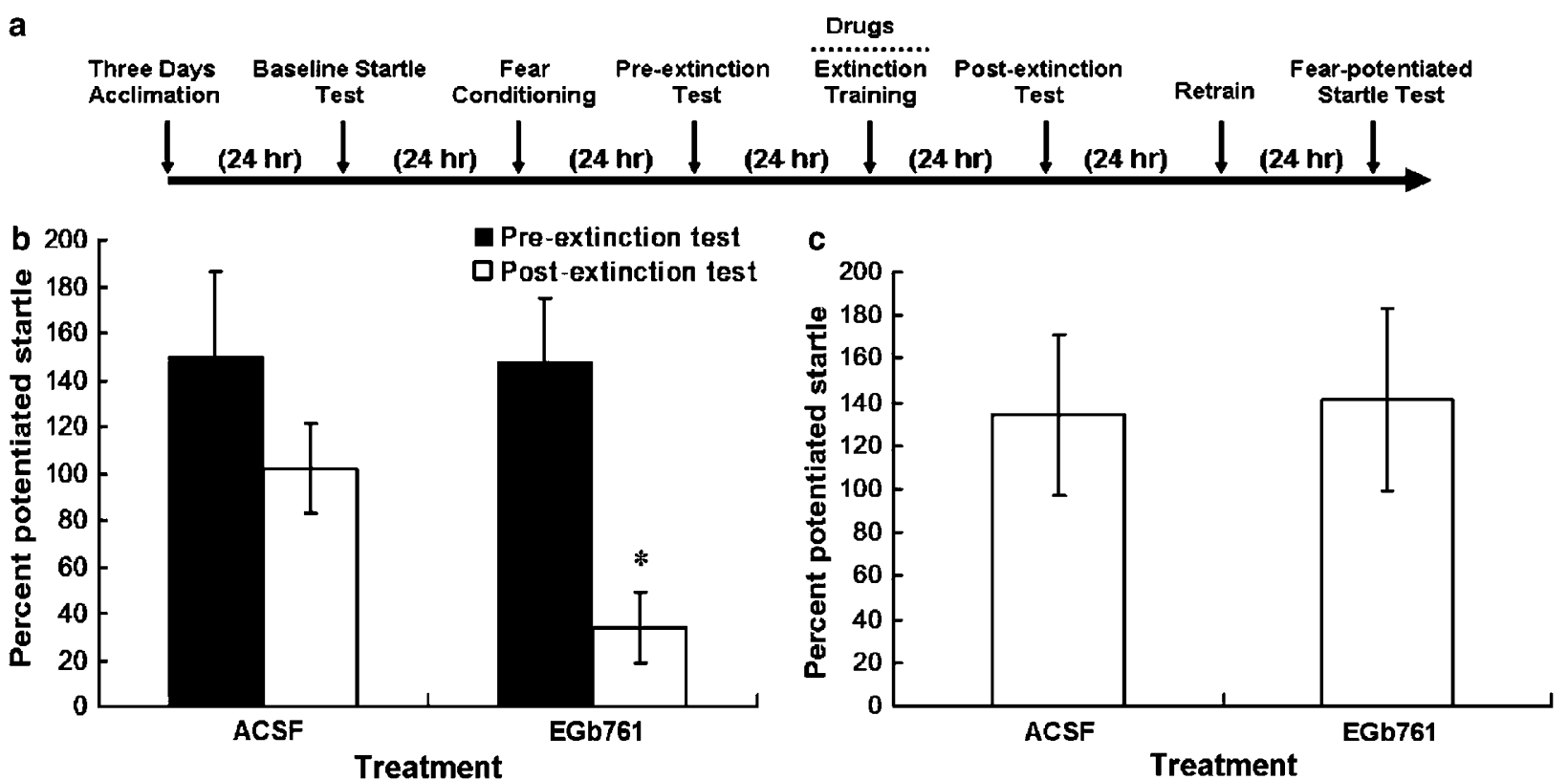

Figure 7 Intra-amygdala infusion of EGb76I facilitated extinction of conditioned fear. (a) Timeline of procedures for experiment 7. (b) Cannula was placed in the BLA. Percent fear-potentiated startle measured in a pre-extinction test and in a postextinction test. Rats in each group underwent either ACSF or EGb76I before a single session of extinction training. After $24 \mathrm{~h}$, animals were tested for fear-potentiated startle in the absence of drug. Data are presented as the mean $\pm \mathrm{SEM}, * P<0.01$ compared to the control group. (c) Cannula tip placements transcribed onto atlas plates adapted from Paxinos and Watson (1997).

into the BLA immediately before extinction training. After $24 \mathrm{~h}$, rats were tested for FPS in the absence of drugs. Intraamygdala infusion of EGb761 enhanced extinction compared to the control group $\left(\mathrm{t}_{(14)}=2.53, P<0.05\right)$. To test for toxicity of EGb761, all rats were retrained and tested $24 \mathrm{~h}$ later. Animals previously injected with ACSF or EGb761 showed a strong FPS (Figure 7b), indicating that EGb761 did not have a nonspecific toxic effect. These results suggested the BLA were involved in the facilitation effect of EGb761 on extinction.

\section{DISCUSSION}

We found that either systemic or intra-amygdaloid administration of Ginkgo biloba EGb761 extract facilitated extinction of conditioned fear (Figure $1 \mathrm{~b}$ and $7 \mathrm{~b}$ ). That this facilitation effect depended on presentation of the CS rather than simple contextual exposure to the experimental environment indicated it was not the result of impaired expression of conditioned fear or accelerated forgetting (Figure 2b). Rats previously injected with EGb761 showed a significant FPS after retraining. Thus, the facilitation appeared to result from an acute drug effect rather than from a toxic action (Figure 1c). The facilitation effect of EGb761 could not be attributed to its nonspecific effects on startle response (Figure $3 \mathrm{~b}$ ). Furthermore, administration of EGb761 immediately after extinction training did not show any facilitation of extinction (Figure $4 \mathrm{~b}$ ), suggesting that facilitation contributed to the acquisition phase of extinction learning. Finally, the Western blot and ERK1/2 inhibitor results (Figure 5b) implied that an amygdaloid ERK1/2 signal cascade participated in the facilitation effect of EGb761 on extinction.
Converging evidence from a variety of studies indicates that the process of extinction can be enhanced with pharmacological intervention (Walker et al, 2002; Ledgerwood et al, 2003, 2004; Yang et al, 2005b). Ours is the first study we know of showing that acute systemic administration of EGb761 facilitated extinction of conditioned fear. Recently, glutamate NMDA receptor agonist DCS and glucocorticoid receptor agonist dexamethasone are documented to facilitate extinction of conditioned fear (Walker et al, 2002; Yang et al, 2005b). Either before or after extinction training, systemic injections of DCS (Ledgerwood et al, 2003; Yang and $\mathrm{Lu}, 2005$ ) or dexamethasone (Yang et al, 2005b) facilitated extinction of conditioned fear. When EGb761 was administered immediately after extinction training, it did not show any facilitation. This suggested that the facilitation effect of EGb761 contributed to the acquisition phase instead of consolidation phase of extinction learning. EGb761 can enhance acetylcholine (Defeudis, 1991) and norepinephrine (Taylor, 1992) transmission. EGb761 may achieve its effect on the extinction of fear memory by stimulating norepinephrine release during fear conditioning, and enhance the perception of fear and anxiety-inducing stimuli and fear-related behavior. EGb761 also inhibits acetylcholinesterase (AChE), the metabolizing enzyme of acetylcholine (Das et al, 2002). The inhibition of $\mathrm{AChE}$ is presently the most accepted and recognized therapeutic marker in the development of cognitive enhancers (Enz et al, 1993; Siddiqui and Levey, 1999; Das et al, 2002). Administration of EGb761 may help animals recruit cognitive resources when presented with ambiguous, discrepant, or potentially threatening stimuli. In addition, EGb761 may facilitate the recollection of conditioned fear, which may help the animal to identify the role of conditioned stimuli during the extinction training phase. 
Consistent with current findings showed exogenous administration of norepinephrine before fear conditioning results in long-term fear memory formation (Ferry et al, 1999; Das et al, 2002). It is still not clear that EGb761 did not clearly affect the expression of FPS. It must be noted that the method we used may not have been sensitive enough to pick up any enhancing effect of EGb761 on the expression of conditioned fear.

EGb761 promotes flow of cerebral blood (Krieglstein et al, 1995), which is associated with improvements in cognitive function in brain damaged subjects (Defeudis, 1991). EGb761 also enhances cognitive function in aged people suffering from insufficient cerebral blood flow (Krieglstein et al, 1995). Therefore, EGb761 may facilitate memory by enhancing cerebral blood flow to the brain regions involved in extinction memory formation. Numerous studies suggest that the BLA is essential for extinction. We recently proved that activation of amygdaloid NMDA glutamate receptors or glucocorticoid receptors facilitates extinction of conditioned fear (Yang and Lu, 2005; Yang et al, 2005b). Other than the BLA, several brain regions including the dorsal hippocampus (DH), and the medial prefrontal cortex (mPFC) are also important for extinction (Davis, 2000; Davis et al, 2000; Quirk et al, 2000; Vienna et al, 2001; Herry and Garcia, 2002; Myers and Davis, 2002). Accumulative evidence indicates that potentiation of prefrontal activity following extinction seems to be implicated in the long-term memory processes of extinction (Milad and Quirk, 2002; Herry and Garcia, 2003; Hugues et al, 2004). Recently, Quirk and co-workers showed that lesion of the ventral mPFC delay the recall of fear extinction in rats (Lebrón et al, 2004). Furthermore, consolidation of fear extinction requires protein synthesis in the mPFC (Santini et al, 2004). Experiments that include local infusion of EGb761 into these regions are required to identify the target sites responsible for the facilitation effect of EGb761.

Numerous signaling cascades that include mitogen activated protein kinase (MAPKs), phosphatidylinositol 3-kinase (PI-3 kinase), calcineurin, calcium/calmodulindependent protein kinase II (CAMKII), and cAMP-dependent protein kinase (PKA) signaling pathways are known to be involved in the extinction of conditioned fear ( $\mathrm{Lu}$ et al, 2001; Lin et al, 2003a, b; Szapiro et al, 2003). There are two major subfamilies of MAPKs that include extracellular signal-regulated kinase (ERK1/2) and p38. Our results showed the extinction training induced amygdaloid ERK1/ 2 phosphorylation was elevated by EGb761 and that intraamygdala infusion of ERK1/2 inhibitor PD98059 blocked the facilitation effect of EGb761. Since we only used the ERK1/2 inhibitor, we cannot exclude the possibility that other signaling pathways are also involved in the EGb761 facilitation effect. Further experiments such as local infusion of specific inhibitors into $\mathrm{mPFC}, \mathrm{BLA}$, and hippocampus are required to identify related signal cascades responsible for the facilitation effect of EGb761.

\section{CONCLUSIONS}

In conclusion, we report that even a single dose of EGb761 can facilitate extinction of conditioned fear. Both systemic and intra-amygdaloid administration of EGb761 enhanced extinction memories when given before extinction training. This enhancement was blocked by treatment with ERK1/2 inhibitor (PD98059). Our findings match previous findings by indicating that the extinction process can be accelerated by pharmacological interventions. EGb761 may serve as a useful adjunct in the treatment of anxiety disorders and other disorders responding to behavioral treatments using the extinction process.

\section{ACKNOWLEDGEMENTS}

This work was supported by grants from the National Science Council, Taiwan (NSC93-2320-B-003-003) and National Taiwan Normal University ORD93-C (T9407000008). Our gratitude also goes to the Academic Paper Editing Clinic, National Taiwan Normal University.

\section{REFERENCES}

Campeau S, Davis M (1995). Involvement of the central nucleus and basolateral complex of the amygdala in fear conditioning measured with fear-potentiated startle in rats trained concurrently with auditory and visual conditioned stimuli. J Neurosci 15: 2301-2311.

Cassella J, Davis M (1986). The design and calibration of a startle measurement system. Physiol Behav 36: 377-383.

Clostre F (2000). Ginkgo biloba extract (EGb761). State of knowledge in the dawn of the year 2000. Ann Pharm Fr 57: 1S8-1S88.

Curtis-Prior P, Vere D, Fray P (1999). Therapeutic value of Ginkgo biloba in reducing symptoms of decline in mental function. J Pharm Pharmacol 51: 535-541.

Das A, Shanker G, Nath C, Pal R, Singh S, Singh HA (2002). Comparative study in rodents of standardized extracts of Bacopa monniera and Ginkgo biloba: anticholinesterase and cognitive enhancing activities. Pharmacol Biochem Behav 73: 893-900.

Davis M (2000). The role of the amygdala in conditioned and unconditioned fear and anxiety. In: Aggleton JP (ed). The Amygdala, Vol 2. Oxford University Press: Oxford, United Kingdom. pp 213-287.

Davis M, Falls WA, Gewirtz J (2000). Neural systems involved in fear inhibition: Extinction and conditioned inhibition. In: Myslobodsky M, Weiner I (eds). Contemporary Issues in Modeling Psychopathology. Kluwer Academic Publishers: Boston. pp 113-142.

Defeudis FV (1991). Ginkgo biloba Extract (EGb 761): Pharmacological Activities and Clinical Applications. Elsevier: Amsterdam.

Diamond BJ, Shifflett C, Feiwel N (2000). Ginkgo biloba extract: mechanisms and clinical indications. Arch Phys Med Rehabil 81: 668-678.

Drieu K (1986). Preparation et definition de l'extrait de Ginkgo biloba. Presse Med 15: 1455-1457.

Enz A, Amstutz R, Boddeke H, Gmelin G, Malanowski J (1993). Brain selective inhibition of acetylcholinesterase: a novel approach to therapy for Alzheimer's disease. Prog Brain Res 98: 431-438.

Ferry B, Roozendaal B, McGaugh JL (1999). Role of norepinephrine in mediating stress hormone regulation of long-term memory storage: a critical involvement of the amygdala. Biol Psychiatry 46: $1140-1152$.

Hasenöhrl RU, Nichau CH, Frisch CH, De Souza Silva MA, Huston JP, Mattern CM et al (1996). Anxiolytic-like effect of combined extracts of Zingiber Officinale and Ginkgo biloba in the elevated plus-maze. Pharmacol Biochem Behav 53: 271-275.

Hasenöhrl RU, Topic B, Frisch C, Häcker R, Mattern CM, Huston JP (1998). Dissociation between anxiolytic and hypomnestic 
effects for combined extracts of Zingiber Officinale and Ginkgo biloba to healthy young volunteers. Pharmacol Biochem Behav 59: 527-535.

Herry C, Garcia R (2002). Prefrontal cortex long-term potentiation but not long-term depression, is associated with the maintenance of extinction of learned fear in mice. J Neurosci 22: 577-583.

Herry C, Garcia R (2003). Behavioral and paired-pulse facilitation analyses of long-lasting depression at excitatory synapses in the medial prefrontal cortex in mice. Behav Brain Res 146: 89-96.

Hugues S, Deschaux O, Garcia R (2004). Postextinction infusion of a mitogen-activated protein kinase inhibitor into the medial prefrontal cortex impairs memory of the extinction of conditioned fear. Learn Mem 11: 540-543.

Krieglstein J, Ausmeier F, Ei-Abhar H, Lippert K, Welsch JM, Rupalla K (1995). Neuroprotective effects of Ginkgo biloba constituents. Eur J Pharm Sci 3: 9-48.

Krieglstein J, Beck T, Seibert A (1986). Influence of an extract of Ginkgo biloba on cerebral blood flow and metabolism. Life Sci 39: 2327-2334.

Landes P (1997). Market report: Whole Food magzine's 2nd annual herb market survey for U.S. health food stores. Herbal Gram 40: 52.

Le Bars PL, Katz MM, Berman N, Itil TM, Freedman AM, Schatzberg AF (1997). A placebo-controlled, double-blind, randomized trial of an extract of Ginkgo biloba for dementia. JAMA 278: 1327-1332.

Le Bars PL, Koeser M, Itil KZ (2000). A 26-week analysis of a double-blind, placebo-controlled trial of the Ginkgo biloba extract EGb761 in dementia. Dementia Geriatr Cognit Disord 11: 230-237.

Lebrón K, Milad MR, Quirk GJ (2004). Delayed recall of fear extinction in rats with lesions of ventral medial prefrontal cortex. Learn Mem 11: 544-548.

Ledgerwood L, Richardson R, Cranney J (2003). Effects of D-cycloserine on extinction of conditioned freezing. Behav Neurosci 117: 341-349.

Ledgerwood L, Richardson R, Cranney J (2004). D-cycloserine and the facilitation of extinction of conditioned fear. Consequences for reinstatement. Behav Neurosci 118: 505-513.

Lin CH, Yeh SH, Leu TH, Chang WC, Wang ST, Gean PW (2003a). Identification of calcineurin as a key signal in the extinction of fear memory. J Neurosci 23: 1574-1579.

Lin CH, Yeh SH, Lu HY, Gean PW (2003b). The similarities and diversities of signal pathways leading to condolidation of conditioning and condsolidation of extinction of fear memory. J Neurosci 23: 8310-8317.

$\mathrm{Lu} \mathrm{KT}$, Walker DL, Davis M (2001). Mitogen-activated protein kinase cascade in the basolateral nucleus of amygdala is involved in extinction of fear-potentiated startle. J Neurosci 21: RC162:1-5.

Milad MR, Quirk GJ (2002). Neurons in medial prefrontal cortex signal memory for fear extinction. Nature 420: 70-74.

Millan SJ, Gacia de la Asuncion J, Pallardo JG, O'Conner E, Martin J, Droy-Lefaiz MT et al (1998). A Ginkgo biloba extract (EGb761) prevents mitochondrial aging by protecting against oxidative stress. Free Radical Biol Med 24: 298-304.
Myers KM, Davis M (2002). Behavioral and neural analysis of extinction. Neuron 36: 567-584.

O'Hara M, Kiefer D, Farrell K, Kemper K (1998). A review of 12 commonly used medicinal herbs. Arch Fam Med 7: 523-536.

Paxinos G, Watson C (1997). The Rat Brain in Stereotaxic Coordinates, 3rd edn. Academic: New York.

Porsolt RD, Martin P, Lenegre A, Fromage S, Drieu K (1990). Effects of an extract of Ginkgo biloba (EGb761) on 'learned helplessness' and other models of stress in rodents. Pharmacol Biochem Behav 36: 963-971.

Quirk GJ, Russo GK, Barron JL, Lebrón K (2000). The role of ventromedial prefrontal cortex in the recovery of extinguished fear. J Neurosci 20: 6225-6231.

Santini E, Ge H, Ren K, de Ortiz SP, Quirk GJ (2004). Consolidation of fear extinction requires protein synthesis in the medial prefrontal cortex. J Neurosci 24: 5704-5710.

Siddiqui MF, Levey AI (1999). Cholinergic therapies in Alzheimer's disease. Drug Future 24: 417-444.

Szapiro G, Vianna MR, McGaugh JL, Medina JH, Izquierdo I (2003). The role of NMDA glutamate receptors, PKA, MAPK, and CAMKII in the hippocampus in extinction of conditioned fear. Hippocampus 13: 53-58.

Taylor JE (1992). In vitro interactions of EGb 761 with biogenic amine uptake sites and NMDA receptors. In: Christen Y, Costintin J, Lacour M (eds). Effects of Ginkgo biloba Extract (EGb 761) on the Central Nervous System. Elservier: Paris. pp 41-46.

Van Dongen MC, Van Rossum E, Kessels AG, Sielhorst HJ, Knipschild PG (2000). The efficacy of ginkgo for elderly people with dementia and age-associated memory impairment: new results of a randomized clinical trial. J Am Geriatr Soc 48: 1183-1194.

Vienna MR, Szapiro G, McGaugh JL, Medina JH, Izquierdo I (2001). Retrieval of memory for fear-motivated training initates extinction requiring protein synthesis in the rat hippocampus. Proc Natl Acad Sci 98: 12251-12254.

Walker DL, Ressler KJ, Lu KT, Davis M (2002). Facilitation of conditioned fear extinction by systemic administration or intraamygdala infusions of D-cycloserine as assessed with fearpotentiated startle in rats. J Neurosci 22: 2343-2351.

Ward CP, Redd K, Williams BM, Caler JR, Luo Y, McCoy JG (2002). Ginkgo biloba extract: cognitive enhancer or antistress buffer. Pharmacol Biochem Behav 72: 913-922.

Yang YL, Lu KT (2005). Facilitation of conditioned fear extinction by $\mathrm{D}$-cycloserine is mediated by mitogen activated protein kinase and PI-3 kinase cascades and requires de novo protein synthesis in basolateral nucleus of amygdala. Neuroscience 134: 247-260.

Yang YL, Chao PK, Lu KT (2005b). Systemic and intra-amygdala administration of glucocorticoid agonist and antagonist modulate extinction of conditioned fear. Neuropsychopharmacology, (advance online publication, 5 October 2005; doi:10.1038/ sj.npp.1300899.)

Yang YL, Su YW, Ng MC, Chang CL, Lu KT (2005a). Extract of Ginkgo biloba EGb 761 facilitates fear conditioning measured by fear-potentiated startle. Neurosci Lett 383: 145-150. 